\title{
Vamos a replicar la vida: Manual de huertos familiares para niñas del programa Abriendo Oportunidades
}

Population Council

Follow this and additional works at: https://knowledgecommons.popcouncil.org/departments_sbsr-pgy How does access to this work benefit you? Let us know!

\section{Recommended Citation}

"Vamos a replicar la vida: Manual de huertos familiares para niñas del programa Abriendo Oportunidades." Ciudad de Guatemala: Population Council, 2021. 


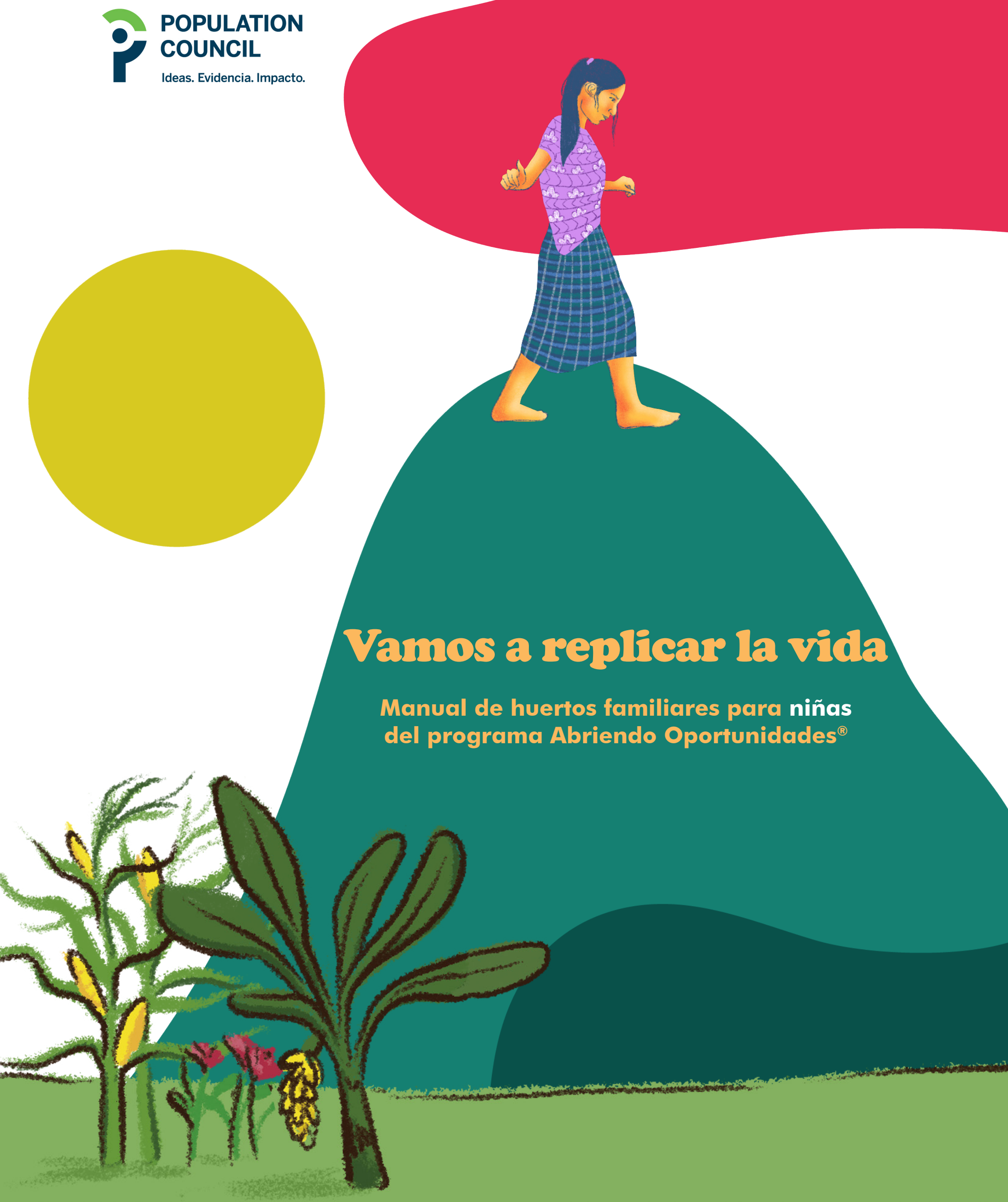


El Population Council enfrenta problemas críticos de salud y desarrollo, desde detener la propagación del VIH hasta mejorar la salud sexual reproductiva y garantizar que los jóvenes lleven una vida plena y productiva. A través de la investigación biomédica, de ciencias sociales y de salud pública en 50 países, trabajamos con nuestros socios para ofrecer soluciones que conduzcan a políticas, programas y tecnologías más efectivas que mejoren vidas en todo el mundo. Establecido en 1952 y con sede en Nueva York, el Council es una organización no gubernamental, sin fines de lucro, gobernada por una junta internacional.

\section{Population Council Guatemala}

19 avenida 0-35 Zona 15, Vista Hermosa 2,

Ciudad de Guatemala, 01015 Guatemala

Tel: +502 2369-0292

popcouncil.org

Insumos de base:

REDMI Aq'ab'al

Texto, diseño y diagramación:

Luis Méndez Salinas y Carmen Lucía Alvarado

Ilustraciones:

Paula Gramajo, Mario Valdez y Leke García

\section{Ciudad de Guatemala, Population Council}

(C) 2020 The Population Council, Inc.

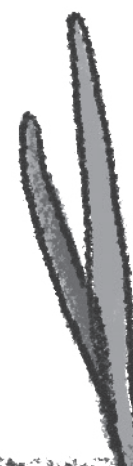




\section{Vamos a replicar la vida \\ Cuadernillo de huertos familiares para niñas del programa Abriendo Oportunidades ${ }^{\circledR}$}

Antes de empezar, recuerda que este cuadernillo es tu compañero. En él quedará registrado todo lo que aprenderás en estas semanas. Cuídalo, protégelo, no lo pierdas.

Este será un camino de siete sesiones en el que la mentora te guiará hacia el conocimiento, la soberanía alimentaria y el porvenir. Aprenderás a hacer un huerto, conversarás con tus amigas y con tu familia sobre tu comunidad, imaginarás el futuro y a aprenderás a hablar con la tierra. Cuando estas semanas terminen, llevarás contigo nuevos aprendizajes, cultivos que tú misma sembraste y un camino que se abre hacia el futuro.

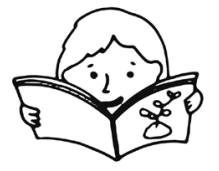

Cuando veas este dibujo, lee con atención los conceptos e historias que aparecen en tu cuadernillo.

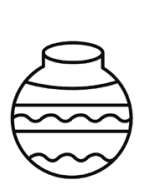

Durante las siguientes semanas elaborarás la decoración para un recipiente donde guardarás las semillas para tu huerto. Esta vasija te indica que cada semana deberás avanzar en ese proyecto.

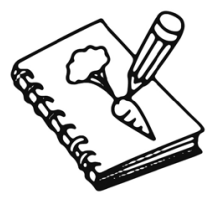

Este dibujo te indica que deberás escribir o dibujar en las páginas de este cuadernillo.

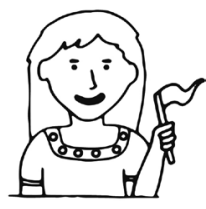

Este dibujo representa a tu mentora. Cuando la veas, pon atención a lo que ella compartirá contigo y con tus compañeras. 


\section{Primera sesión}

\section{La diversidad de cultivos}

Observa tu entorno, verás que en la naturaleza hay diferentes formas de vida. En un pequeño pedazo de tierra conviven muchas especies: árboles, arbustos, hierbas, entonces, los cultivos deben tratar de parecerse a la naturaleza.

Hoy aprenderás qué es la diversidad de cultivos.

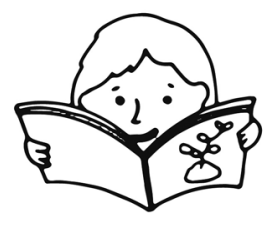

La diversidad de cultivos tiene que ver con las diferentes siembras que realizan las personas en sus terrenos para obtener productos variados en las diferentes épocas del año. Es fundamental que los seres humanos tengamos diversas siembras para garantizar el bienestar de nuestra familia.

Recuerda que mientras más variados sean nuestros alimentos, es mejor para nuestra salud. Y mientras más variados sean los cultivos, es mejor para la salud de la tierra.

Comemos muchas cosas que vienen de la tierra. Por ejemplo: semillas, raíces, frutas, flores, hierbas, verduras. Piensa en la variedad de sabores y formas que tienen tus alimentos.
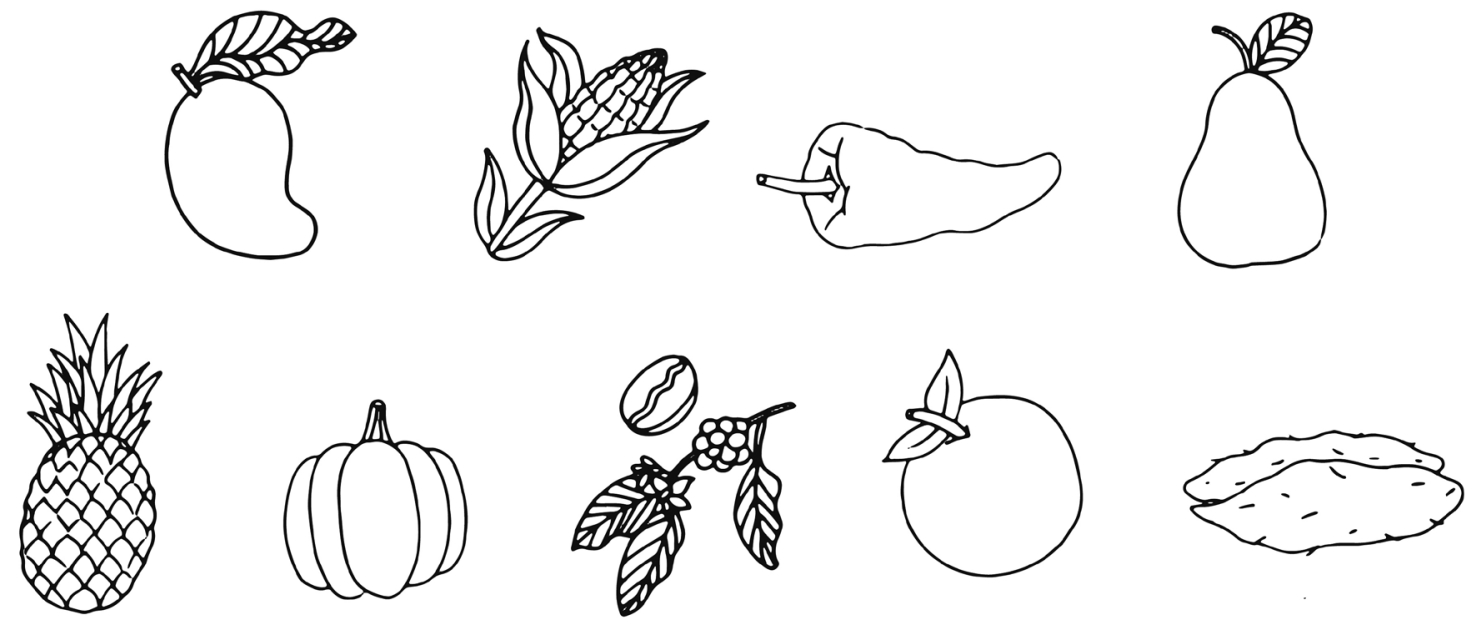


\section{Los colores que nos alimentan}

A continuación encontrarás dos espacios: en el primero deberás dibujar

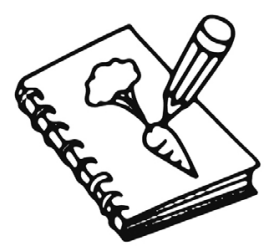
el paisaje que te rodea. Piensa en las montañas, los ríos, el campo que ocupa tu comunidad. Incluye en tu dibujo las áreas en que se producen alimentos: las siembras, los cultivos. Ubica las frutas, las verduras, los granos que sueles comer. En el segundo espacio, dibuja tu propio retrato: tu cara, tu ropa, tu pelo. Cuando los dibujos estén terminados, traza una línea del color de cada alimento, y llévala del cultivo a tu boca. Observa la diversidad de colores que van de los cultivos hacia ti.

Dibuja el paisaje de tu comunidad 


\section{Un recipiente para guardar nuestras semillas}

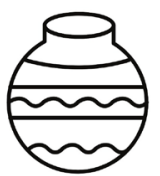

A lo largo de todas estas sesiones crearás tu propio recipiente para guardar las semillas. Irás recogiendo ideas, historias, dibujos que te servirán mucho para decorarlas Aprovecha la oportunidad para preguntarle a tus papás ya tus abuelos sobre las siembras en tu comunidad. ¿̇Qué se siembra? ¿̇Cómo se siembra? Anota las ideas que te compartan:

\section{Para la siguiente sesión}

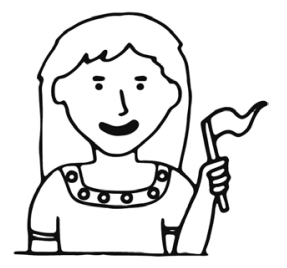

Trata de ubicar semillas en tu casa. No necesitarás muchas. Piensa en frijoles, maíces y cualquier otra semilla que esté a tu alcance. Llévala contigo a la próxima sesión. 


\section{Segunda sesión}

Todo surge de las semillas

\section{Conoce los siguientes conceptos:}

Una semilla es aquella parte de una planta ya existente, capaz de ser fuente de la creación de una nueva planta del mismo tipo.

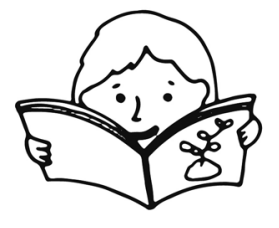

Un embrión es el origen del fruto vegetal que se encuentra en la semilla.

La germinación es el proceso mediante el cual un embrión se desarrolla hasta convertirse en una planta. Este proceso se lleva a cabo cuando el embrión se hincha y la cubierta de la semilla se rompe, y sucede debajo de la tierra.

\section{La importancia de las semillas}

Las semillas son los bebés de nuestra comida. Tienen que entrar a la tierra, porque la tierra es la mamá de todas. Y ahí, como un bebé, las semillas crecen y van a salir a la luz cuando estén listas. Por más chiquitas que sean, adentro van plantas, frutas, verduras, raíces; solamente necesitan el cuidado adecuado, y el tiempo suficiente para que pronto se conviertan en el alimento que nos nutre, nos da fuerza, y nos hace sentir y pensar.

¿Qué semillas lograste encontrar en tu casa? 
El paso de la semilla al alimento

Sigue la instrucciones que te indicará la mentora para llenar el siguiente cuadro:

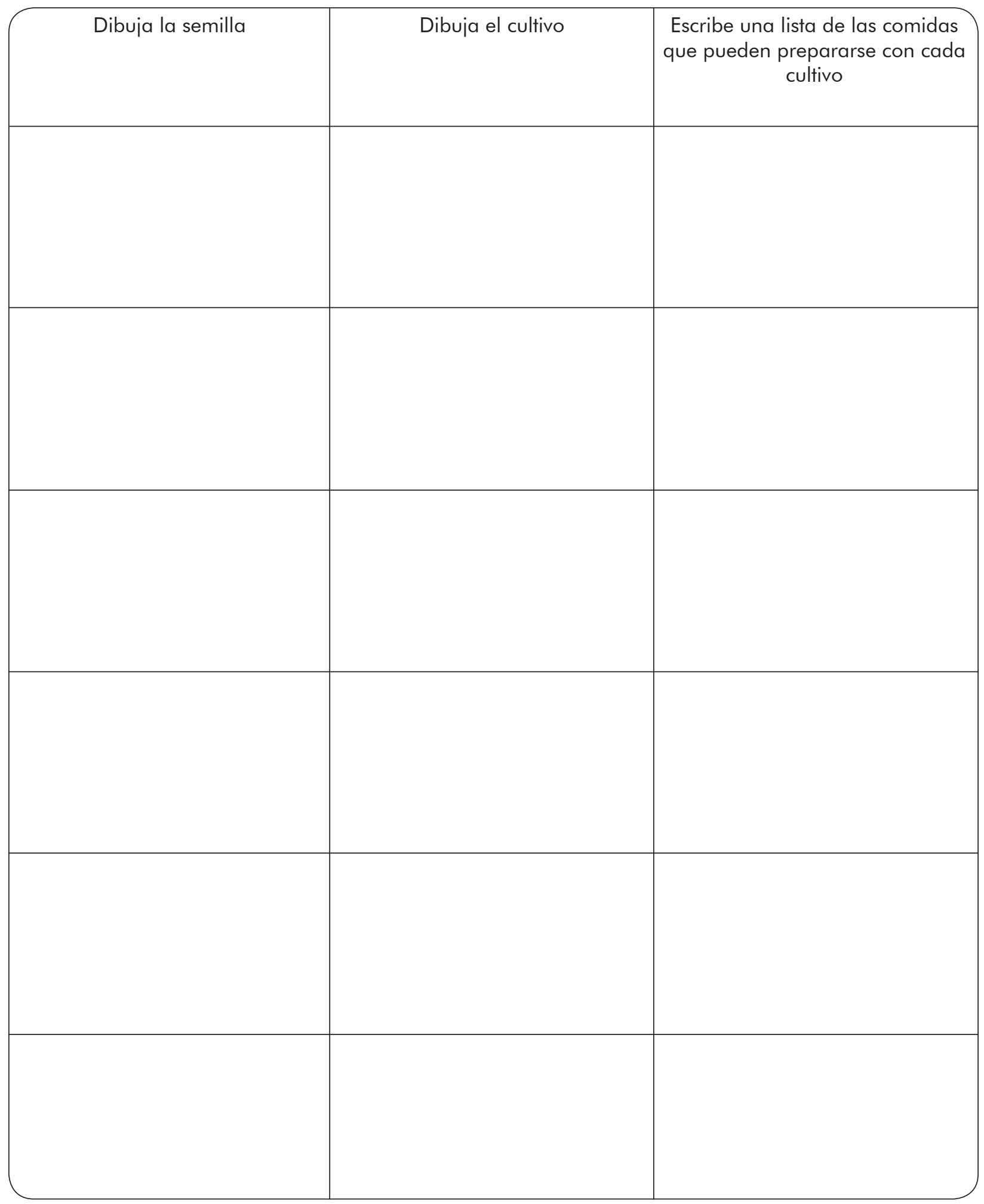

8 Vamos a replicar lavida 


\section{E1 tiempo y la tierra trabajan juntos}

Cuando las semillas entran a la tierra, empiezan a transformarse. Algunas semillas necesitan pocos días, otras necesitan más. Lo más importante es tener paciencia, porque el camino que lleva a una semilla hasta convertirse en un alimento no es inmediato, y además de paciencia necesita mucha atención.

Aquí te damos algunos ejemplos de los días que tardan las siguientes especies o semillas en germinar:

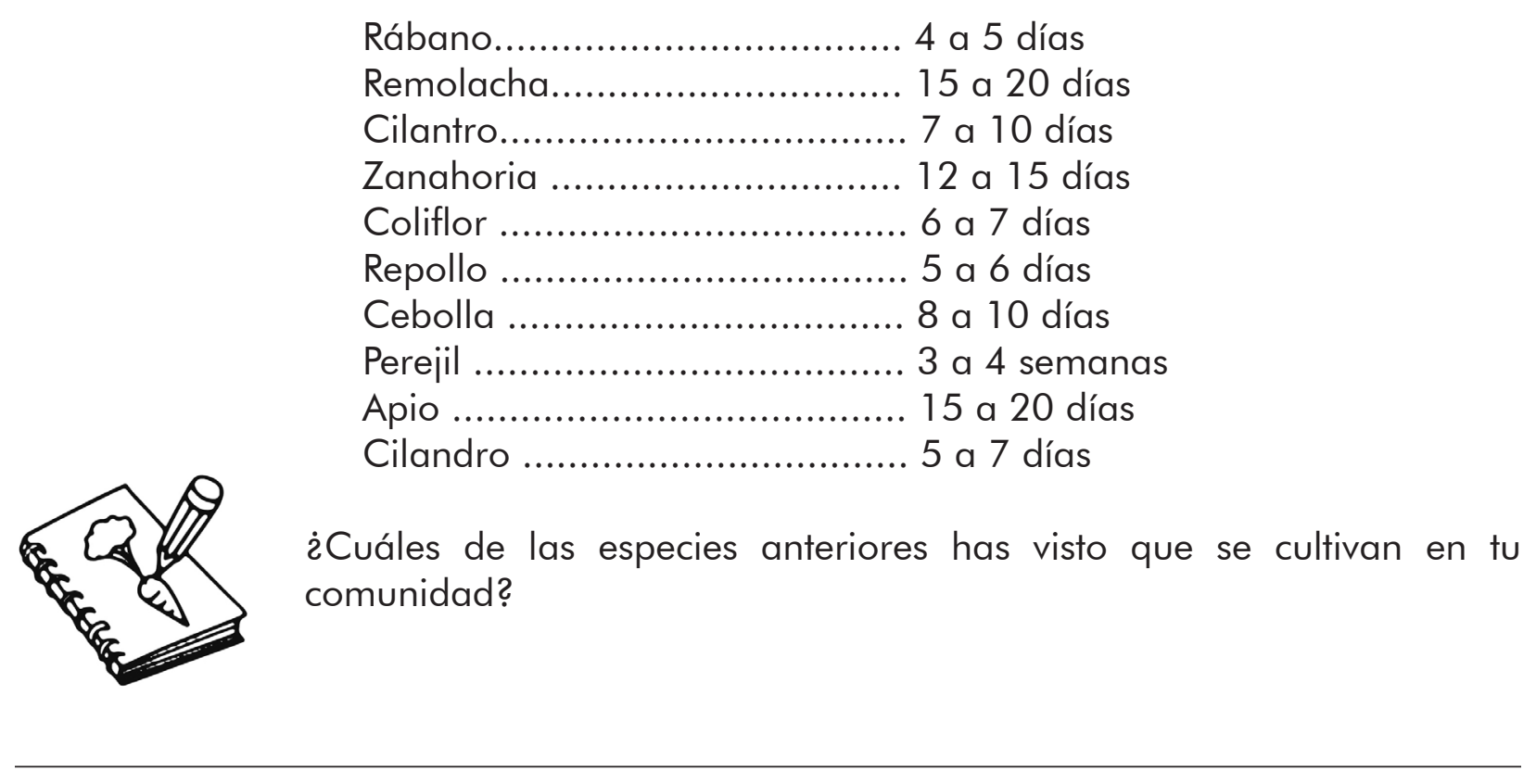

¿Qué otras especies son comunes en los campos que conoces de tu comunidad? 


\section{Somos hermanas de las semillas}

Sigue las indicaciones de tu mentora para realizar esta actividad que te hará moverte, bailar y sentir.

1. Siente que eres una semilla.

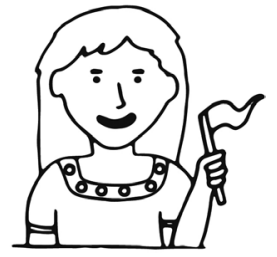

2. Siente que esa semilla crece y te conviertes en planta.

3. Ya creciste. Ya eres grande. Representa con movimientos lo que serás en el futuro (maestra, doctora, artista, etc.)

4. Vuelve a ser una semilla. Inicia el ciclo de la vida otra vez.

\section{Un recipiente para guardar nuestras semillas}

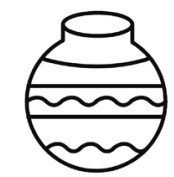

Durante la semana, platica con tus abuelos. Pregúntales si conocen alguna historia sobre las semillas. Aquí podrás anotar las historias que tus abuelos o tus papás te cuenten: 
En base a lo que platicaste con tus abuelos, ¿̇te gustaría inventar algún cuento que tenga como protagonista a una semilla, o que cuente cómo se siembra en tu comunidad? Escríbelo aquí: 
Realiza algún dibujo que resuma los cuentos que recogiste o inventaste durante la semana:

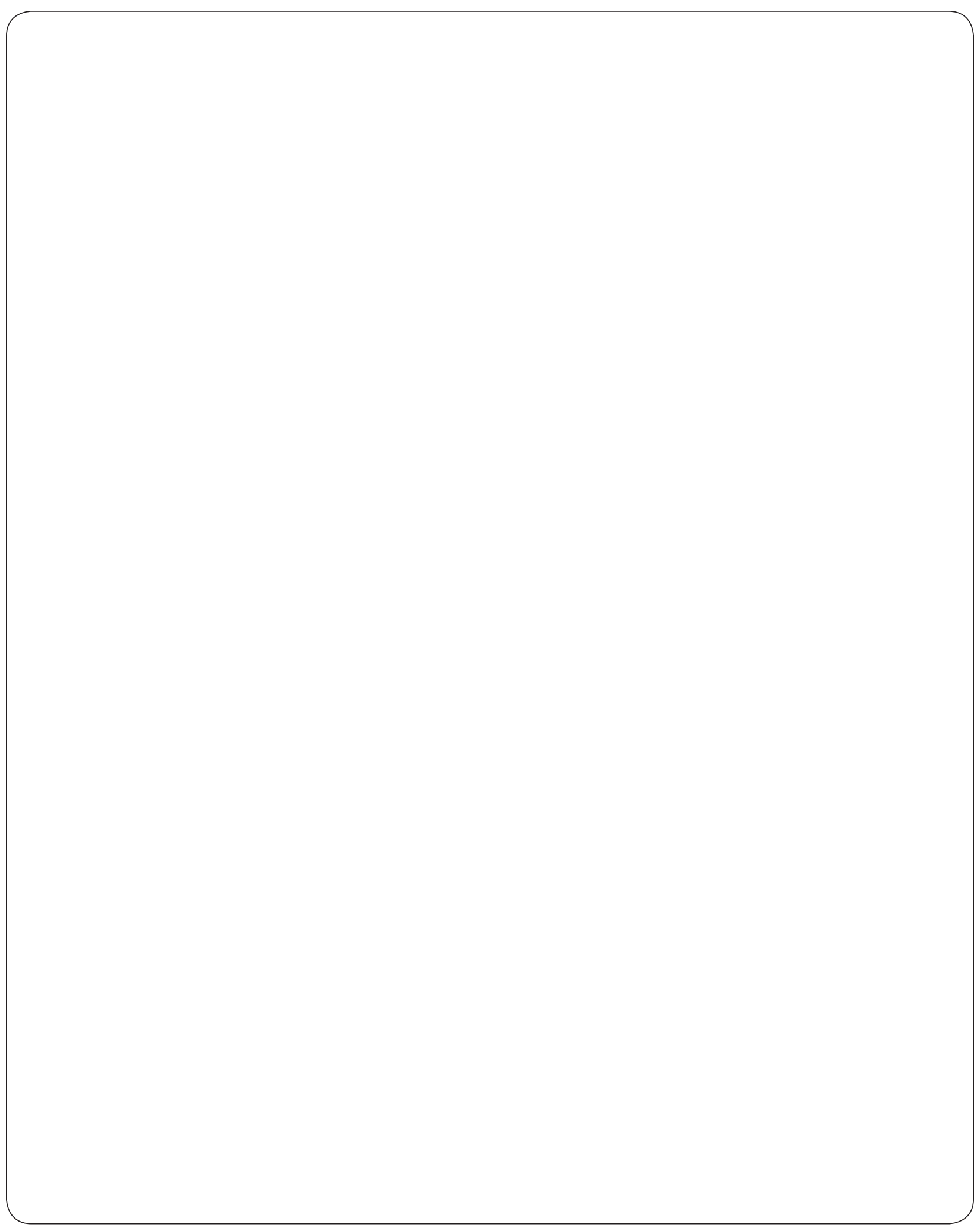

12 Vamos a replicar la vida 


\section{Tercera sesión}

\section{El huerto familiar}

\section{¿Has oído hablar de los huertos familiares?}

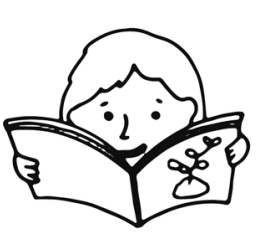

Un huerto familiar es el lugar donde cada familia cultiva hortalizas, verduras, frutas, plantas medicinales, hierbas comestibles y árboles frutales que complementarán su alimentación. También puede ser un lugar para criar aves de corral. Estos huertos deben estar lo más cerca posible de su casa, para asegurar su cuidado y vigilancia.

\section{La tierra no nos cobra por darnos alimentos}

¿Qué pasaría si buena parte de lo que comemos nace en nuestra propia casa?

¿Qué te gustaría sembrar en tu propia casa para comerlo constantemente?

¿Has pensado en la posibilidad de hacer crecer tu propia comida? 
¿Qué podrían hacer tus papás con el dinero que no gastarían en el mercado al cultivar ellos mismos el alimento?

Recuerda: nuestros huertos deben ser variados, deben parecerse a la variedad de la naturaleza.

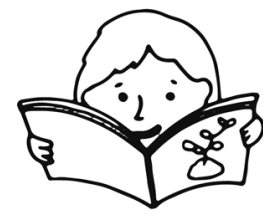

Cuando una variedad de alimentos nace y crece en nuestra propia tierra, podemos variar nuestra alimentación, gastamos menos dinero, podemos intercambiar lo que sembramos, incluso vender alimentos a personas de la comunidad a precios más bajos porque han crecido ahí mismo y no se tuvo que pagar por el traslado. Podemos hacer conservas, salsas, chirmoles, refrescos. Incluso pensar en abrir un lugar en donde la gente coma los alimentos de nuestro huerto a precios accesibles. A eso se refiere la soberanía alimentaria: a la posibilidad de hacernos más independientes con el fruto de nuestro propio trabajo.

\section{La invocación de las especies}

Escucha con atención las indicaciones de tu mentora para participar con tus compañeras en la siguiente dinámica. Usarás tus manos, cantarás, recordarás muchos alimentos que crecen en tu entorno.

¿Qué hierbas son las más comunes en tu comunidad? 
¿Qué verduras son las más comunes en tu comunidad?

¿Qué frutas son las más comunes en tu comunidad?

Antes de hacer tu huerto, deberás hacer un plan. En él tendrás que definir los cultivos que plantarás, en qué cantidad y en qué momento del año.

Tienes que tomar en cuenta los siguientes aspectos:

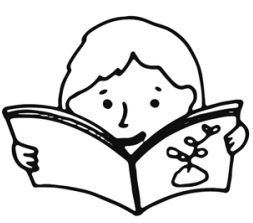

Rotación de cultivos: No conviene cultivar las mismas hortalizas siempre en el mismo lugar de tu huerto. Se debe cambiar el tipo de hortalizas cada temporada. Con este procedimiento se evita que el suelo pierda siempre los mismos nutrientes. Rotar tus cultivos evita que aparezcan muchas malezas, plagas y enfermedades.

Siembra intercalada: Se pueden cultivar dos o más especies en hileras alternas. Con este procedimiento se logra aprovechar mejor la tierra y los nutrientes del suelo.

Siembra escalonada: Hay hortalizas que se pueden sembrar varias veces al año. Con ellas se puede realizar siembras en distintas fechas. Los cultivos escalonados permiten que tengas siempre disponibles ciertos alimentos. Por ejemplo, cada 30 días puedes sembrar las siguientes especies: lechuga, acelga, rábano y cebolla. 


\section{El terreno de tu huerto}

Identifica dónde estará ubicado tu huerto familiar. Toma en cuenta lo siguiente:

- Tu huerto debe estar muy cerca de tu casa, para que puedas cuidarlo constantemente. Lo mejor es que esté en tu propio patio.

- Mantén lo más limpio posible el terreno.

- Es ideal contar con abono orgánico. Pregúntale a tu mentora al respecto, y ella te guiará.

- Riega tu siembra con agua limpia.

- Al escoger el terreno para tu huerto, asegúrate de que tenga bastante sol durante las mañanas.

- Los árboles cercanos te ayudarán a proteger tus cultivos.

- Siempre es bueno pensar en un drenaje o canal de salida para que el exceso de agua no inunde tu huerto.

- Alrededor de tus siembras, identifica un sendero para caminar sin machucar a tus plantitas.

\section{Las formas de sembrar}

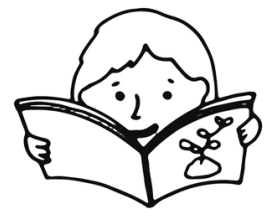

La siembra directa se realiza haciendo un surco y cubriendo la semilla con un poco de tierra. Riégala constantemente hasta que germine. Así podrás sembrar rábano, remolacha, cilandro y zanahoria.

La siembra indirecta consiste en colocar la semilla en un semillero y cuando la plantita tenga cierto tamaño, deberás trasladarla al terreno de tu huerto. Esto se hace cuando las semillas son muy pequeñas, como en el caso del brócoli, coliflor, repollo, cebolla, perejil y apio.

Un aspecto importante que puedes utilizar es hacer una pequeña cama de pino (u otras hojas pequeñas) que servirá como una capa protectora que evitará que la lluvia saque las semillas y las exponga al sol. Además, permitirá la retención de la humedad del suelo y generará la temperatura adecuada para el brote de la semilla.

\section{Las herramientas que deberás utilizar}

Para que no te cueste trabajar en tu huerto, es importante tener las herramientas adecuadas. Estas te ayudarán mucho:

- Azadón: para remover la tierra, sacar malezas y trazar surcos.

- Machete: se usa para despejar terrenos con hierbas altas o arbustos.

- Pala: para cargar y descargar tierra, abono, etc.

- Malla: sirve para circular tu huerto. 
Identifica las herramientas, escribiendo su nombre a la par de los dibujos:
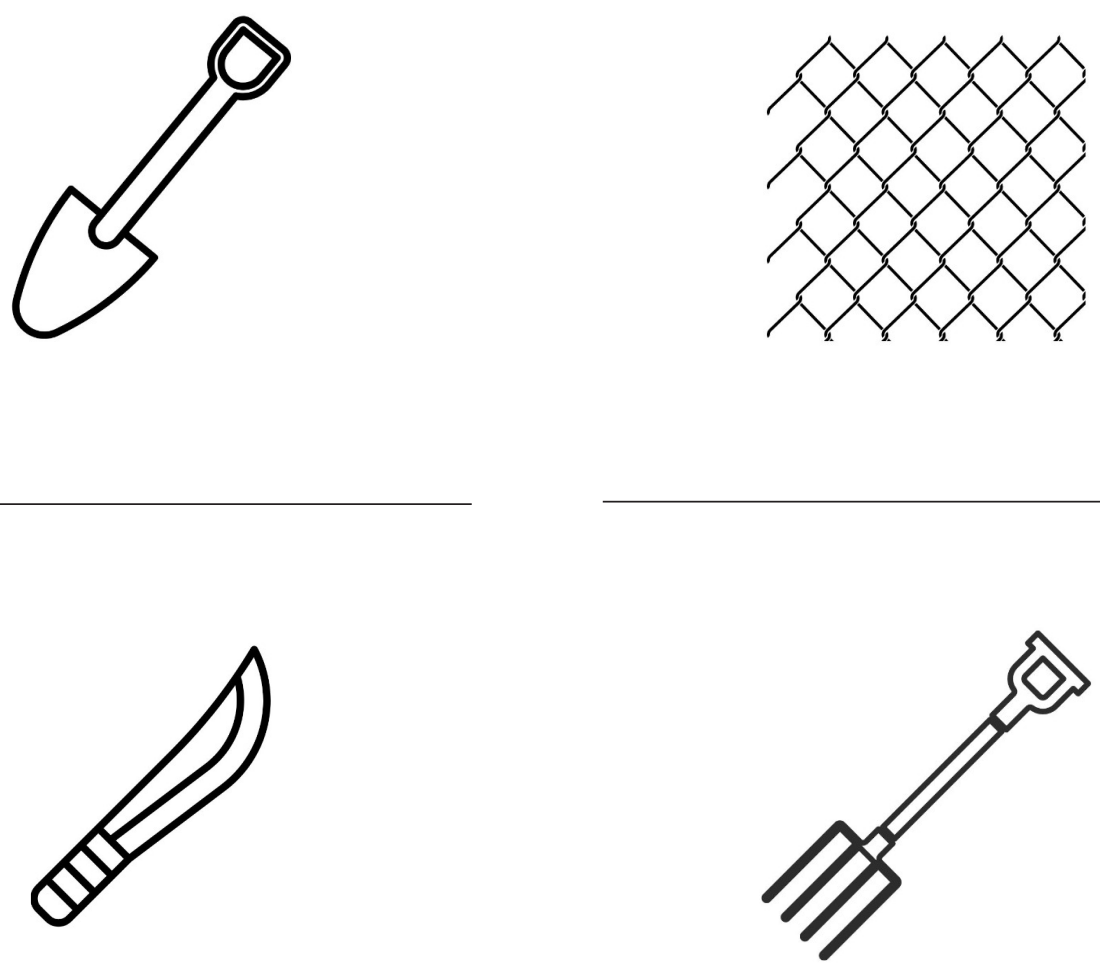

\section{La importancia del abono orgánico}

Uno de los trabajos más necesarios para el cuidado de tu huerto es agregar materia orgánica al suelo. ¿̇Por qué?

- La materia orgánica aumenta la capacidad de los suelos arenosos de retener agua.

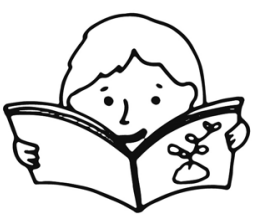

- Ablanda los suelos pesados (arcillosos) mejorando el crecimiento de las raíces.

- Sirve de alimento a los organismos del suelo.

- Proporciona nutrientes necesarios para el crecimiento de las plantas. 


\section{Imaginemos nuestros huertos}

En este cuadro, dibuja cómo esperas que crezcan las plantas en tu huerto. ¿Puedes visualizarlo? Utiliza los colores de las plantas y los frutos, para llenar de vida tu patio. El cuadernillo espera tus dibujos, así como tu patio espera tu huerto.

Sembrar nos garantiza que seguiremos vivos y que pondremos en práctica un ritual que nuestros padres, abuelos y antepasados más lejanos realizaron para garantizar el alimento. Por eso, cuando iniciemos nuestros huertos es importante pedirle permiso a la tierra antes de depositar en ella nuestras semillas. A ella le pediremos que nuestros cultivos sean sanos y abundantes. Además, ofreceremos el fruto de nuestro trabajo a la comunidad a la que pertenecemos, y por eso debemos agradecerle a la tierra la oportunidad de hablar con ella.

Cuando vas a sembrar toda la existencia entra en diálogo contigo. 
Un recipiente para guardar nuestras semillas

Dibuja a los miembros de tu familia.

Pregúntale a tus papás si en la comunidad hay alguna costumbre para sembrar. Anótala aquí: 


\section{Cuarta sesión}

\section{Aprendamos a hablar con la tierra}

La tierra está llena de organismos pequeños y necesita nutrientes para que lo que sembremos logre salir a la luz y crezca de la mejor manera.

Además, recuerda que la tierra se enferma cuando se le exige que produzca mucho más de lo que tiene capacidad de producir y en tiempos más cortos.

\section{El cuidado de nuestro huerto}

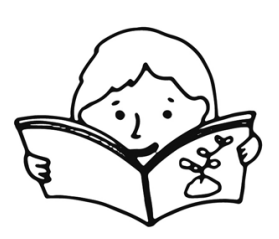

Luego de sembrar nuestras semillas, debemos realizar diversas tareas para mantener nuestro huerto y garantizar que los cultivos crezcan bien. Estas actividades las podrás realizar en compañía de los demás miembros de tu familia. Ten en cuenta que deberás realizar constantemente los siguientes procesos:

Riego: es importante regar los cultivos por lo menos tres veces a la semana a partir de la siembra de las semillas. Es recomendable regar en las primeras horas de la mañana (entre las 5 y las 7 am, aprovechando el rocío) o en la tarde (de 4 a 6 pm) para que el agua no se evapore y aporte al desarrollo de las raíces.

Determinar la humedad: se debe de tomar con la mano una buena cantidad de tierra. Al cerrar el puño, ésta deberá tomar la forma de tu mano. Si la tierra se desintegra rápido es señal de que la humedad es baja y necesita más agua. Si mantiene su forma, significa que la humedad es la correcta. En cambio, si al apretar la tierra con tu mano sale agua, esto nos indicará el exceso de humedad. Cuando esto último suceda, deja más tiempo entre cada riego para evitar el desarrollo de enfermedades en tus cultivos.

Raleo: es una actividad manual que sirve para distanciar cada una de las plantitas que siembres en tu huerto. El distanciamiento ayudará a que cada una crezca de manera adecuada.

Desmalezado: consiste en quitar las malezas que broten junto a tus cultivos, y que les impedirán crecer correctamente, ya que compiten por los nutrientes del suelo, del agua y del sol.

Fertilización: cada cierto tiempo, aplica abono orgánico para enriquecer el suelo de tu huerto. Tu mentora puede guiarte explicándote qué es y cómo puedes obtener abono orgánico. También pregúntale a tus padres y abuelos cómo obtener abono de forma natural. Evita, por todos los medios, utilizar químicos que a largo plazo enferman la tierra. 
Cosecha: la cosecha consiste en recolectar los alimentos que han crecido en tu huerto. Es algo que debe hacerse en el tiempo justo. No te adelantes ni te atrases. A continuación te presentamos un cuadro con el tiempo promedio que tardan las siguientes especies en estar listas:

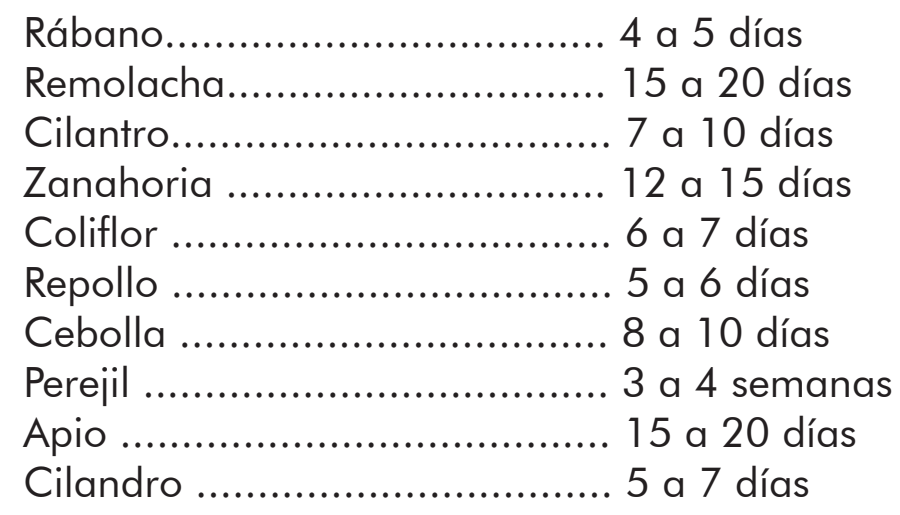

Anota aquí los cuidados que le estás dando a tu huerto:

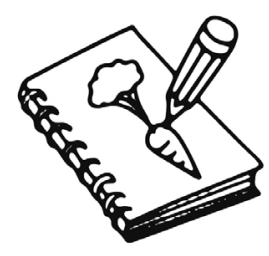


Un recipiente para guardar nuestras semillas

3 Dibújate a ti misma trabajando en tu huerto. Trata de representar las emociones que sientes al estar hablando con la tierra. 


\section{Investiga, escucha, cuenta}

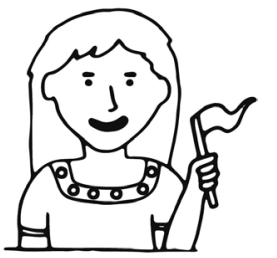

Es importante que te comuniques con tus padres y con tus abuelos. Ellos te ayudarán a conocer la historia de tu familia y de tu comunidad. Pregúntales qué saben del origen de la comunidad, qué han vivido, qué les contaron sus mayores. Anota los resultados de tu investigación. 


\section{Quinta sesión}

\section{Somos lo que comemos}

\section{Ver hacia nuestro interior}

Tu mentora te compartirá este texto y te dará indicaciones que deberás seguir con atención. Queremos que lo tengas aquí, para que puedas leerlo y sentirlo en cualquier momento, y para que lo compartas con las demás.

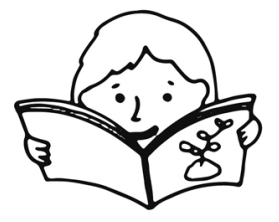

Soy de la tierra. Inicié este camino hace mucho, cuando siendo una semilla pequeñita la tierra me tragó.

Ella, que es tan grande, que es tan buena, me llevó adentro suyo y me dio de comer.

Pequeñísimas energías entraban en mí, me hacían sentir parte de algo mucho, pero mucho más grande que yo.

Me daba agua, me chineaba entre su oscuridad. Casi sentía que me cantaba para que siguiera con los ojos cerrados.

Con el tiempo, mi piel empezó a cambiar, se hizo más suave y húmeda.

Sentí que tenía que estirarme, moverme lentamente, quizá cambiar de posición.

Así salió de mí una pequeña raíz blanca. Ese día fue muy feliz porque sentía que empezaba a acariciar a mi madre la tierra. Yo le decía 'gracias' con mi pequeña raíz.

Muy pronto nacieron otras raíces.

Ya no era solo una semilla. Estaba cambiando de forma.

Desde fuera sentí que una voz me llamaba, que me decía: 'Ven hacia mí, avanza'.

Y yo sentía que la tierra me decía: 'Sí, ve. Ve con la luz que te está llamando'.

Y así lo hice, porque la luz me llamaba aunque yo no la podía ver.

Me fue creciendo más el cuerpo, ahora no era solo raíz.

Para buscar la luz, una nueva forma me nació: un pequeño tallo que quería ver todo lo que había afuera de mi madre la tierra.

Así, un día, broté. Sentí por primera vez el aire y la luz me dio la bienvenida. Mi cuerpo siguió creciendo, adentro y afuera de la tierra.

Bebí de la lluvia, bailé con el viento, me alimenté de la luz.

Ahora he crecido. Mi tallo es ancho y me salieron ramas y hojas.

Con ellas abrazo la vida.

Ya no soy una semilla, pero ahora me han nacido a mí muchas pequeñas semillas. 
Las lanzo en espera de manos que las tomen por mí, que las pongan en la tierra, para que otra vez ella las cuide en su oscuridad, y las haga crecer hasta que vengan acá, en donde yo estoy ahora, y seamos muchas más, y sigamos bailando con el viento, bebiendo de la lluvia y siempre regresando a la tierra.

\section{Somos 10 que comemos}

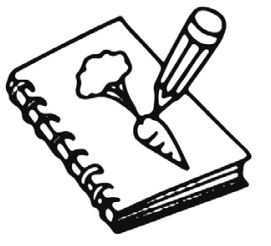

Después de la actividad grupal que tu mentora dirigirá, responde las siguientes preguntas luego de haber reflexionado con tus compañeras:

¿Qué es lo que más comen las jóvenes de esta comunidad?

¿Qué es lo que menos comen?

¿Qué es lo más accesible que tienen para comer? 
¿Dónde se producen esos alimentos?

¿Qué quisieran comer más, pero no es accesible en la comunidad?

¿Todas comen lo mismo?

¿̇Los alimentos que comen son suficientes para el trabajo y el esfuerzo que realizan cada día?

¿Qué sabemos de nutrición en nuestra comunidad?

26 Vamos a replicar la vida 
¿Sabes que las "chucherías" son dañinas para la salud?

¿Por qué crees que en las tiendas hay tantas chucherías?

¿Qué podemos hacer para evitar comerlas?

Recuerda que:

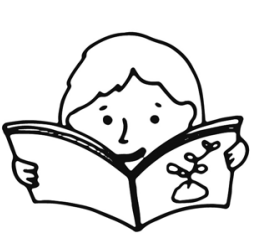

Nuestra salud y nuestros ánimos para la vida dependen de lo que comemos y la forma en que comemos. Comer no es lo mismo que nutrirse. Cada cuerpo necesita cierto tipo de nutrientes para estar en buenas condiciones y nutrirse de diferentes alimentos para aprovechar toda la riqueza que tiene la tierra. 


\section{Un recipiente para guardar nuestras semillas}

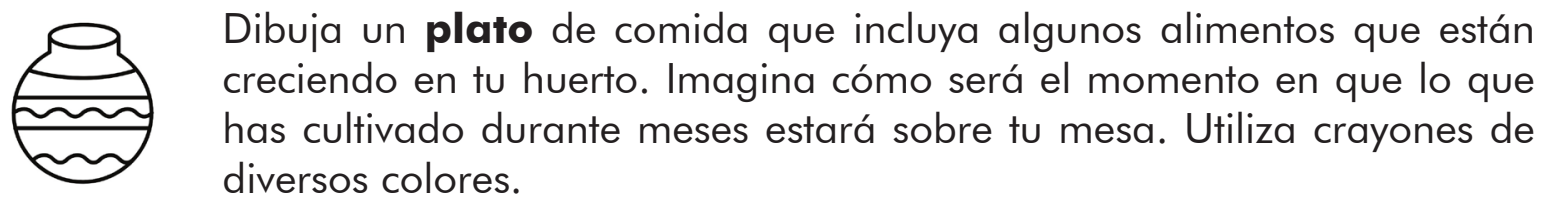

Debajo del espacio para tu dibujo encontrarás una serie de cuadros en blanco, que deberás pintar con cada uno de los crayones que utilices al dibujar tu plato.

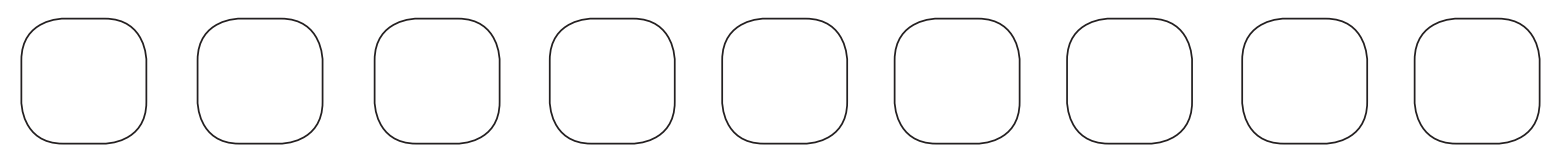




\section{Para la próxima sesión}

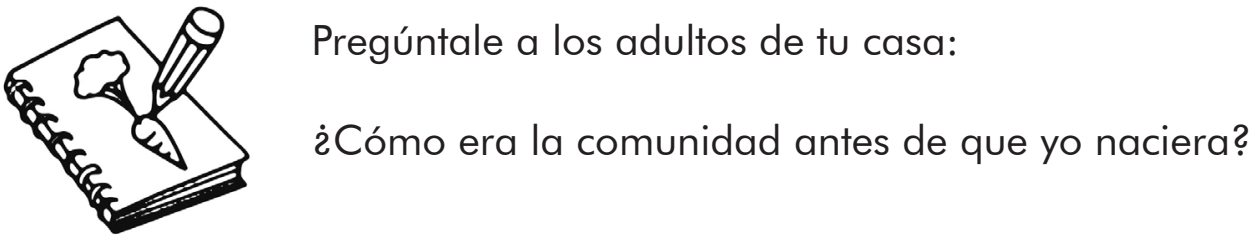

¿Qué se comía antes?

¿Cómo se preparaban los alimentos?

¿Cómo se servían las comidas?

¿Qué cosas han cambiado? ¿Se sigue sembrando de la misma forma? 


\section{Sexta sesión}

\section{Imagino lo que seré}

El desarrollo no debe verse solo como un logro personal, sino como el resultado de la vida en comunidad. Cada una de nosotras es valiosa para que las cosas buenas pasen en el lugar en que vivimos.

Tu mentora te hará las siguientes preguntas, a las que podrás volver siempre que necesites pensar en ti misma:

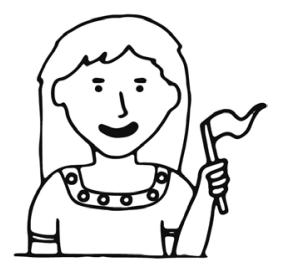

¿Qué es lo que más te gusta hacer?

$\dot{2}$ Te gusta imaginar cosas?

¿Te gusta escuchar a la gente?

$\dot{2} T$ e gusta el deporte?

¿Te gusta bailar?

¿Te gusta cantar?

¿Te gusta enseñar?

¿Te gusta cocinar?

$\dot{2} T$ e gusta sembrar?

¿Te gusta ver las estrellas?

¿ंTe gusta pensar?

¿Te gustan los números?

$\dot{2} T$ e gusta escribir?

$\dot{2} T$ e gusta pintar?

¿Te gusta saber cómo era el pasado?

¿Te gusta usar las manos para construir algo?

¿Te gusta observar las plantas?

¿Te gustan los animales?

¿Te gusta organizar a tus amigas para hacer cosas juntas?

¿Te gusta curar a las personas?

$\dot{2} T$ e gusta combinar colores?

¿ Te gusta viajar?

¿Te gusta vender y comprar?

$\dot{2} T$ g gusta hacer tu ropa?

¿Qué te hace feliz? 
Anota aquí tus pensamientos sobre estas preguntas: 
Te has preguntado żqué serás en el futuro? Aquí te dejamos algunas opciones:

$\begin{array}{ccc}\text { Psicóloga } & \text { Deportista } & \text { Pintora } \\ \text { Arquitecta } & \text { Cantante } & \text { Constructora } \\ \text { Antropóloga } & \text { Escritora } & \text { Futbolista } \\ \text { Escultora } & \text { Bióloga } & \text { Transportista } \\ \text { Bailarina } & \text { Veterinaria } & \text { Trabajadora Social } \\ \text { Economista } & \text { Ingeniera } & \text { Servidora pública } \\ \text { Comerciante } & \text { Doctora } & \text { Enfermera } \\ \text { Cocinera } & \text { Astrónoma } & \text { Guía turística } \\ \text { Agrónoma } & \text { Maestra } & \text { Tejedora }\end{array}$

Recuerda que a través de lo que tú hagas, puedes colaborar para que tu comunidad sea mejor.

\section{Evalúa tu comunidad}

A continuación encontrarás una serie de preguntas sobre las condiciones de vida en tu comunidad. Si la respuesta es positiva, pinta la carita feliz. Si las cosas no son del todo buenas, pinta la carita seria. Y si la situación es muy mala, pinta la carita triste. Esto nos ayudará a entender en qué debemos concentrarnos para mejorar nuestra situación.

¿Hay luz en todas las casas?

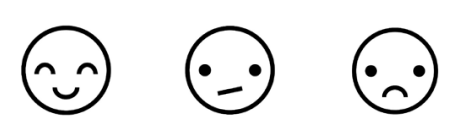

¿̇Todas las niñas y niños van a la escuela?

$$
\text { (-) } \odot
$$


¿Hay instituto básico en la comunidad?

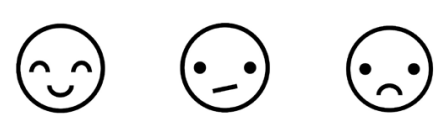

$\dot{2}$ Hay instituto de carreras (diversificado) en la comunidad?

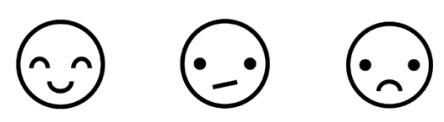

¿Hay diversidad de cultivos?

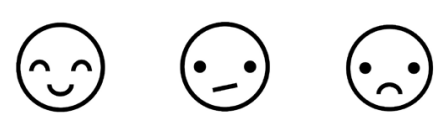

¿̇Todos pueden comprar su comida en el mercado?

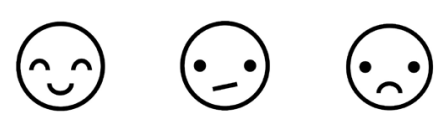

¿Hay acceso a agua potable?

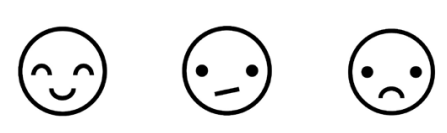

¿Está limpio el municipio?

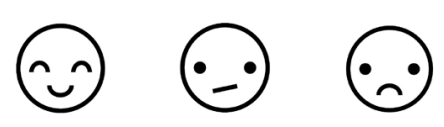

¿La gente está conforme con los COCODES (autoridades)?

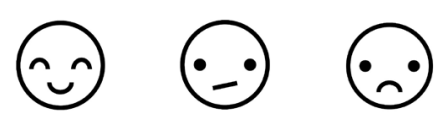

¿Está conforme la comunidad con las autoridades municipales?

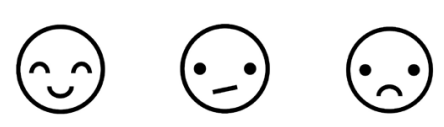




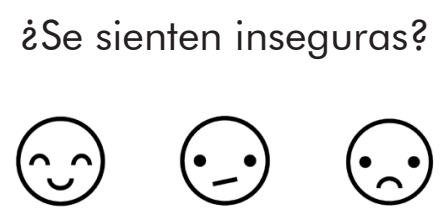

¿Hay espacios para la recreación?

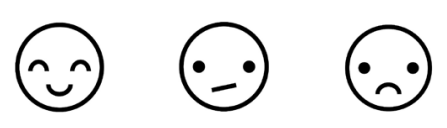

¿Hay espacios para convivir y dialogar?

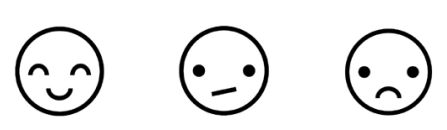

¿Hay hospital o centro de salud?

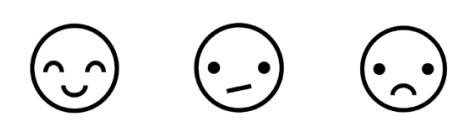

¿Es fácil obtener medicinas?

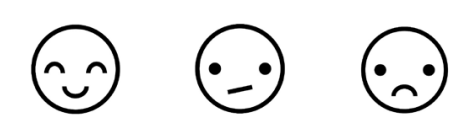

¿Hay bosques cercanos?

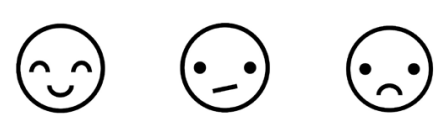

¿La gente sabe su idioma materno?

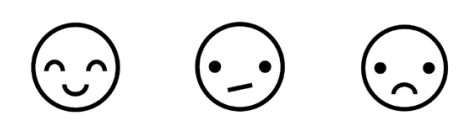

¿Todos saben leer y escribir?

$\odot \odot \odot$ 
Cuenta el número de caritas felices, serias y tristes que pintaste. ¿Qué te dice eso de tu comunidad?

Caritas felices:

Caritas serias:

Caritas tristes:

Cuando te preguntes cómo será el futuro, recuerda esto:

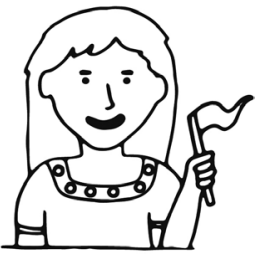

Ustedes son semillas y guardan muchas posibilidades, que pueden crecer, multiplicarse y alimentar a su comunidad. Así como han trabajado en su huerto para que produzca alimento, así tienen que trabajar en ustedes mismas, para que todo eso que llevan dentro crezca y se multiplique. Su vida puede convertirse es un huerto lleno de vida y posibilidades.

\section{Un recipiente para guardar nuestras semillas}

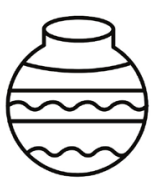

Durante las últimas semanas has recolectado historias, conversaciones y dibujos que te serán útiles para contar una historia. Lo harás a través de una vasija o recipiente que te servirá siempre para guardar las semillas que sembrarás en tu huerto.

Con los materiales que te proporcione tu mentora, organiza la historia que contarás en tu recipiente y plásmala pintando directamente en él o recortando los dibujos y pegándolos en la superficie externa. Trata de que quede lo mejor posible, pues será un objeto que te acompañará en el futuro y a través del cual podrás mostrarle a la gente de tu comunidad algo de tu historia.

Asegúrate de tomar en cuenta los siguientes aspectos:

- La historia de tu comunidad

- Las siembras que se realizan en tu comunidad

- Los miembros de tu familia

- El paisaje de tu comunidad

- Tú y tu huerto

- Tú y tus alimentos 
Revisa lo que has escrito y dibujado en este cuadernillo, y copia en los cuadros siguientes al menos 4 o 5 escenas que luego trasladarás a tu vasija:

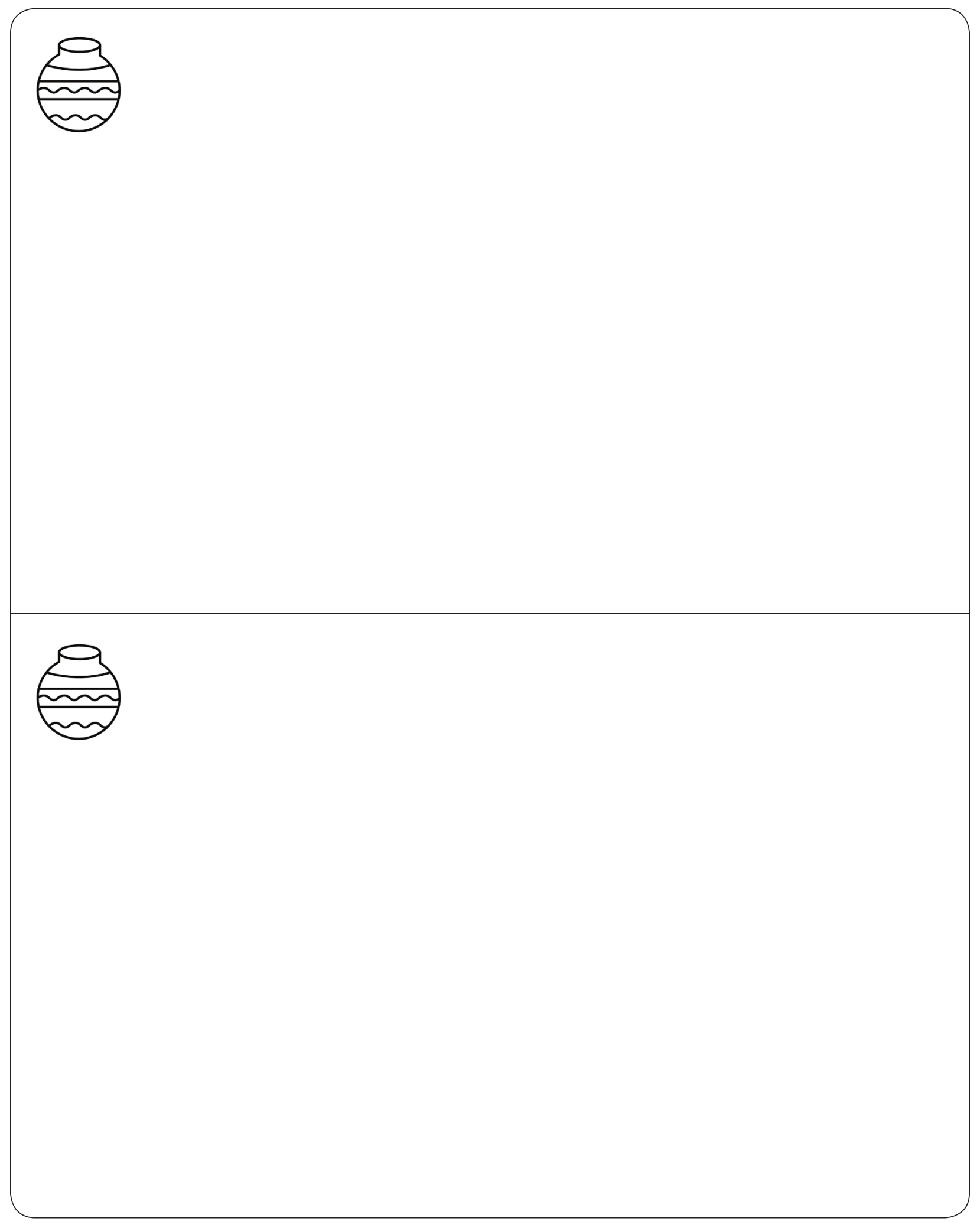

36 Vamos a replicar la vida 


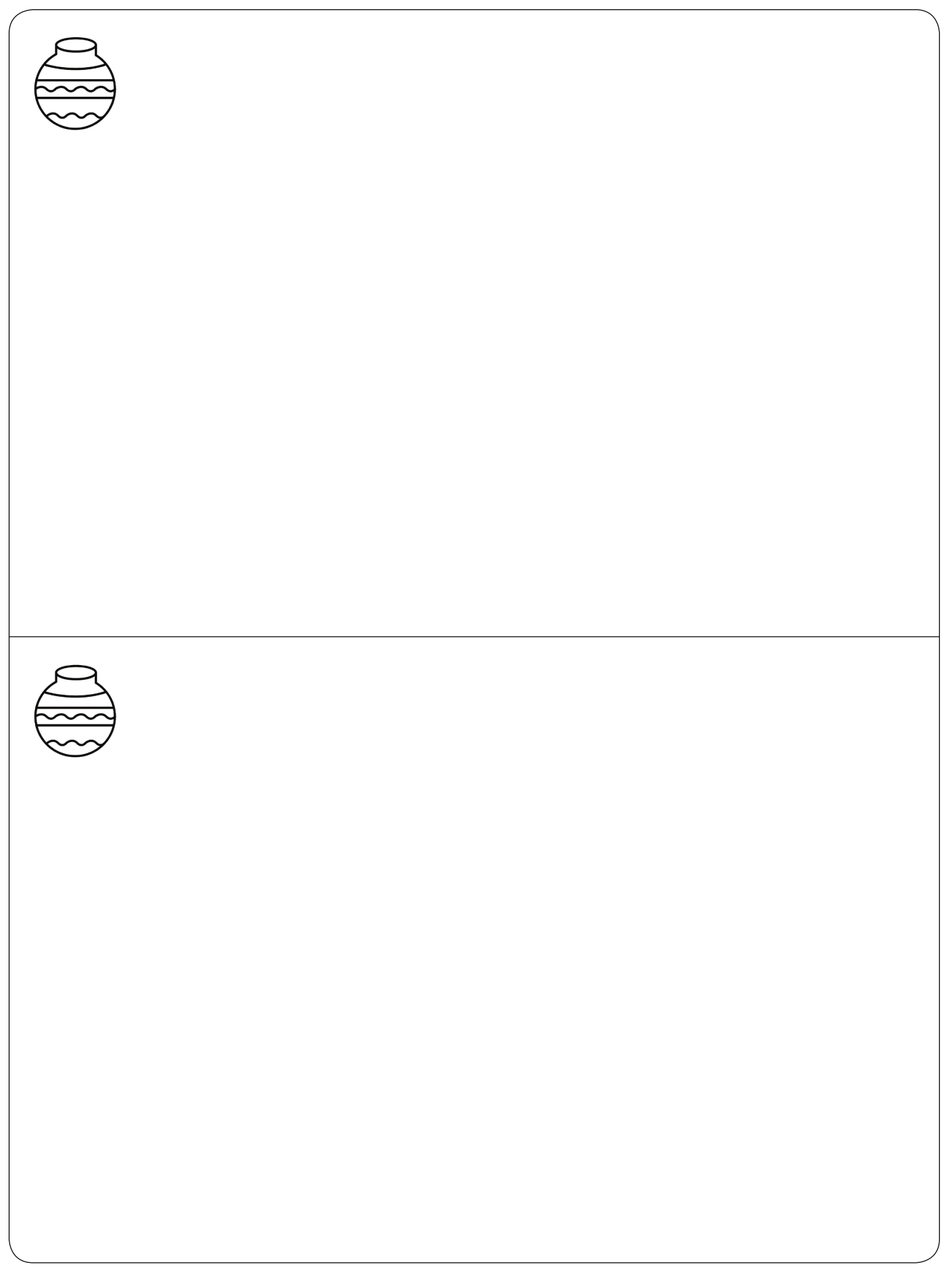

Manual de huertos familiares para niñas

37 


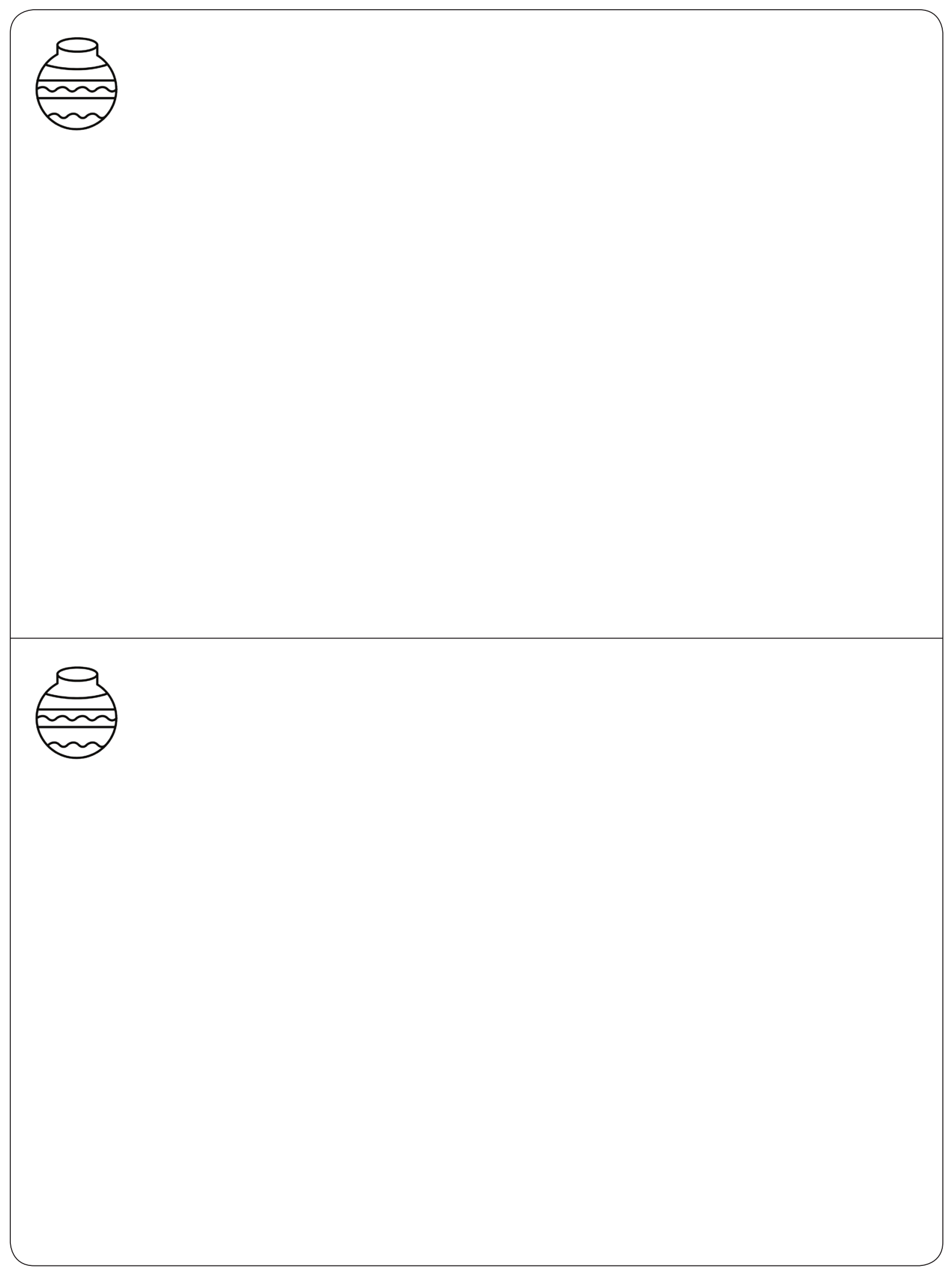

38 Vamos a replicar la vida 


\section{Séptima sesión}

\section{Un regalo para mi comunidad}

Este camino de siete semanas se ha convertido en una forma de conocerse unas a otras y de conocerse a sí mismas. Ahora han iniciado un huerto, han preguntado por el pasado, han buscado adentro de sí mismas su vocación, han aprendido a ver de diferentes formas a su comunidad, han imaginado el futuro, han aprendido a contar su historia con palabras, formas y colores.

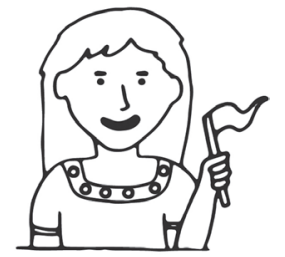

Ser una niña es muy importante, y tu forma de aprender, de hacer crecer la vida y de cuidarla es una parte esencial de tu ser. Ahora debes pensar en todo lo que tu huerto traerá, en la memoria de tus antepasados y en todo el futuro que, como las semillas, está esperando para brotar de ti misma.

\section{Presenta tu vasija}

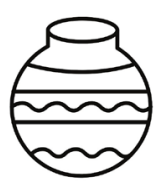

El día de presentar tu vasija ha llegado, y tu mentora te guiará para pensar el espacio en que vas a colocarla y que será apreciado por los miembros de tu comunidad. Recuerda que en ella están reunidas todas las historias, todos los aprendizajes que has tenido en este recorrido.

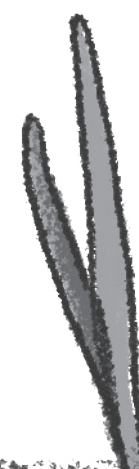



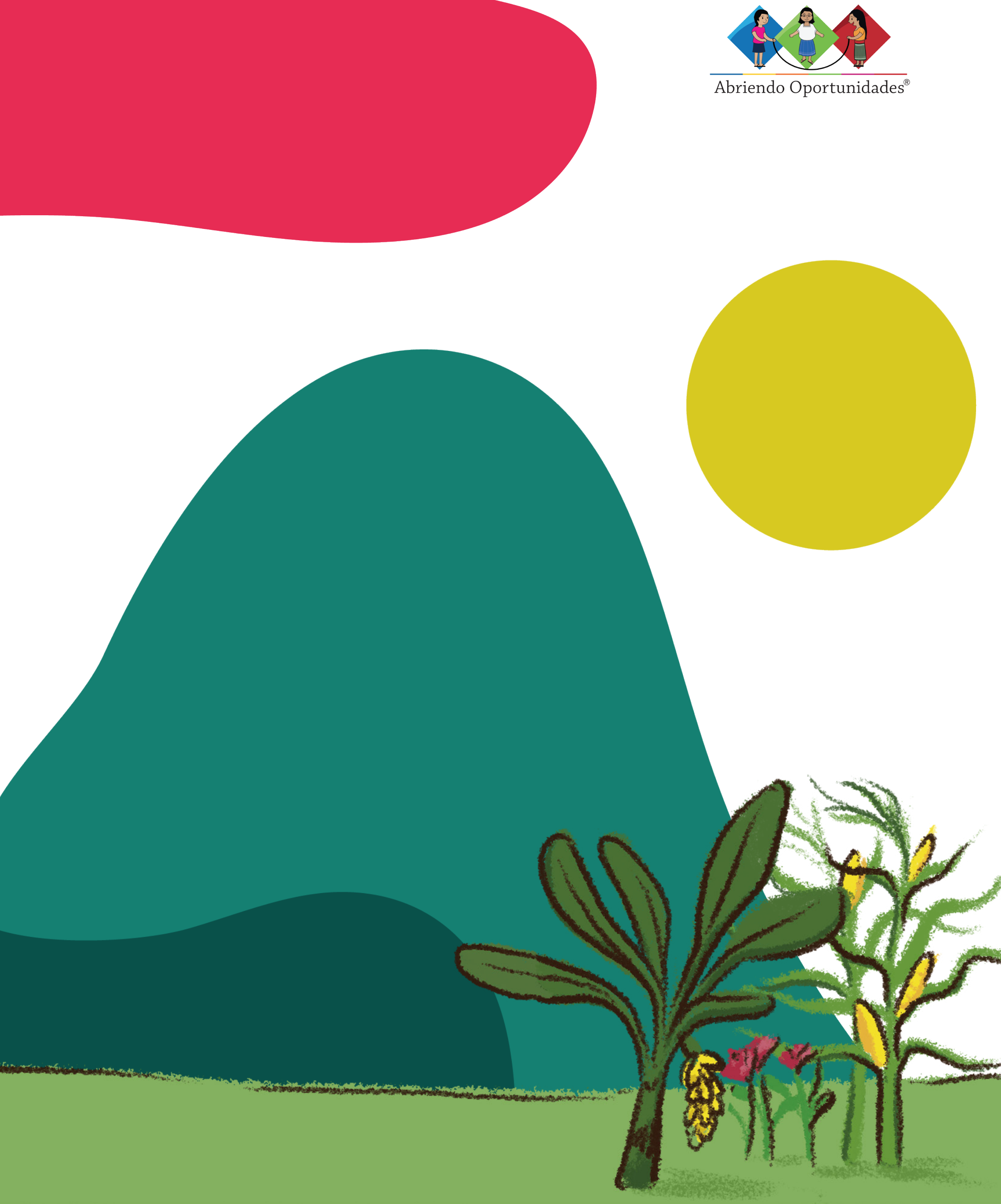